\title{
Putatively asexual chrysophytes have meiotic genes: evidence from transcriptomic data
}

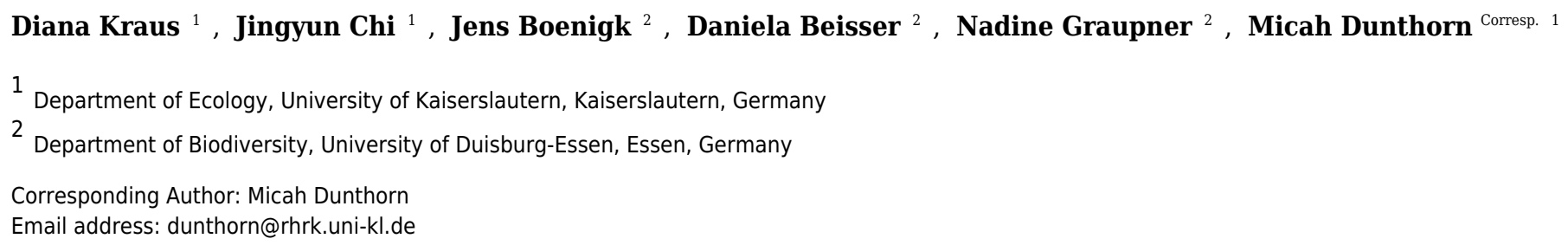

Chrysophytes are a large group of heterotrophic, phototrophic, or even mixotrophic protists that are abundant in aquatic as well as terrestrial environments. Although much is known about chrysophyte biology and ecology, it is unknown if they are sexual or not. Here we use available transcriptomes of 18 isolates of 15 putatively asexual species to inventory the presence of genes used in meiosis. Since we were able to detect a set of nine meiosis-specific and 29 meiosis-related genes shared by the chrysophytes, we conclude that they are secretively sexual and therefore should be investigated further using genome sequencing to uncover any missed genes from the transcriptomes. 


\section{Putatively asexual chrysophytes have meiotic genes:}

\section{4 evidence from transcriptomic data}

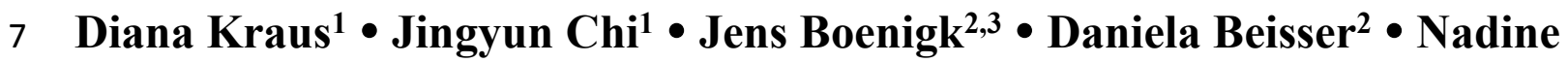

8 Graupner $^{2} \bullet$ Micah Dunthorn ${ }^{1,3,4}$

9

${ }^{1}$ Department of Ecology, University of Kaiserslautern, Erwin Schrödinger Straße 14, D-67663

Kaiserslautern, Germany

2 Department of Biodiversity, University of Duisburg-Essen, Universitätsstraße 5, D-45117

Essen, Germany

${ }^{3}$ Centre for Water and Environmental Research (ZWU), University of Duisburg-Essen,

Universitätsstraße 2, D-45141 Essen, Germany

${ }^{4}$ Department of Eukaryotic Microbiology, University of Duisburg-Essen, Universitätsstraße 5,

Email: Micah Dunthorn

21 micah.dunthorn@uni-due.de 
22 Abstract Chrysophytes are a large group of heterotrophic, phototrophic, or even mixotrophic

23 protists that are abundant in aquatic as well as terrestrial environments. Although much is known

24 about chrysophyte biology and ecology, it is unknown if they are sexual or not. Here we use

25 available transcriptomes of 18 isolates of 15 putatively asexual species to inventory the presence

26 of genes used in meiosis. Since we were able to detect a set of nine meiosis-specific and 29

27 meiosis-related genes shared by the chrysophytes, we conclude that they are secretively sexual

28 and therefore should be investigated further using genome sequencing to uncover any missed

29 genes from the transcriptomes.

30

31 Keywords Asexuality. Meiosis . Crossover pathways . Sex 


\section{Introduction}

33 The Chrysophyceae Pascher 1914 are a morphologically diverse group of flagellates that are

34 among the dominant protists in aquatic and terrestrial habitats (Boenigk \& Arndt 2002; Foissner 1987; Kristiansen \& Preisig 2001; Kristiansen \& Škaloud 2017; Sandgren 1988). These protists serve as excellent models in ecology, ecophysiology, and evolution (Boenigk 2008; Graupner et al. 2018), because of their wide range of nutritional strategies. Their ecological importance of the chrysophytes is derived from the heterotrophic and mixotrophic taxa being important grazers of bacteria (del Campo \& Massana 2011; Ekelund et al. 2001; Finlay \& Esteban 1998), and the phototrophic and mixotrophic taxa being a large component of the primary producers in oligotrophic freshwaters (Kristiansen \& Škaloud 2017; Wolfe \& Siver 2013).

Despite their known ecological importance, chrysophyte taxon richness and species boundaries are difficult to infer. For example, there are some taxa with morphological characters of high diagnostic value such as in Paraphysomonas (Scoble \& Cavalier-Smith) and Synura (Siver \& Lott 2016), taxa with morphological characters of uncertain taxonomic value such as in the Dinobryon divergens complex (Jost et al. 2010), and taxa that are largely missing much morphological characters such as many colorless non-scaled taxa (Grossmann et al. 2016). Assessing reproductive isolation in these taxa may offer a starting point for a consistent taxonomic revision and recognition of species boundaries based on mating abilities. In general, chrysophytes are assumed to be capable of sex, even though conclusive evidence has not been demonstrated for either meiosis or the fusion of meiotic products from different individuals (Kristiansen \& Škaloud 2017). Possible formation of zygotes was observed in Dinobryon and Synura using morphological observations, but changes in ploidy were not evaluated (Bourrelly 
54 1957; Fott 1959; Sandgren 1983; Wawrik 1972). These morphological studies are also restricted

55

56

57

58

to a handful of taxa and the distribution of sex within the chrysophytes remains unknown.

Meiotic sex is assumed to be retained in most macro-organismic eukaryotes because asexuality can lead to extinction over time (Bell 1982; Maynard Smith 1978). However, sex is often not easily observable is many microbial eukaryotic groups, which can lack distinctive morphological differences between the sexes or we do not know the right environmental conditions to induce sex in the laboratory (Dunthorn \& Katz 2010; Schurko et al. 2009; Speijer et al. 2015). In the absence of direct observations of sex (e.g., O'Gorman et al. 2009) and in the absence of known sexual mating types (e.g., Corradi \& Brachmann 2017), one of the strongest molecular signatures of secretive sex in putative asexual protists is the presence of meiotic genes. If the meiotic genes are found in their genomes, then the protein products are likely being used for sex, otherwise they would have been lost over evolutionary time (Normark et al. 2003;

Schurko \& Logsdon 2008). While genomic data are usually used for such meiotic gene inventories in protists (Chi et al. 2014a; Dunthorn et al. 2017; Malik et al. 2008; Patil et al. 2015; Ramesh et al. 2005; Tekle et al. 2017), expressed sequence tag (EST) have also been used, although genes can be missing from an EST library if they are not being expressed at the time the protist was collected and analyzed for a secretive sexual stage (Chi et al. 2014b).

Transcriptomic data from 18 chrysophyte isolates, representing 15 different species that were either photo-, mixo-, or hetero-trophic, were recently used to gain insights into nutritional strategies and phylogenetic relationships (Beisser et al. 2017). Within the chrysophytes able to perform photosynthesis, the transcriptomes revealed a higher expression of genes participating in photosynthesis, photosynthesis-antenna proteins, porphyrin and chlorophyll metabolism, carbon fixation and carotenoid biosynthesis, while in the heterotrophic strains there was a higher 
77 expression of genes involved in nutrient absorption, environmental information processing and

78 various transporters (e.g., monosaccharide, peptide, lipid transporters). Here we used those same

7918 chrysophyte transcriptomes from Beisser et al. (2017) for a meiotic gene inventory to evaluate

80 if these putatively asexual protists are capable of sex. Following Chi et al. (2014a), the presence

81 and absence of these genes were placed into the context that there are two meiotic crossover

82 pathways: class I pathway, which relies on meiotic-specific genes and can include a

83 synaptonemal complex; and class II pathway, which uses meiotic-related genes that are also

84 involved in mitosis (Loidl 2016). 


\section{Materials and methods}

86 From Beisser et al. (2017), sequenced and cleaned transcriptomic data were taken for 18

87 chrysophytes strains of 15 species: Acrispumella msimbaziensis (strain JBAF33),

88 Apoikiospumella mondseeiensis (strain JBM08), Cornospumella fuschlensis (strain A-R4-D6),

89 Dinobryon sp. (strain FU22KAK), Dinobryon sp. (strain LO226KS), Epipyxis sp. (strain

PR26KG), Ochromonas or Spumella sp. (strain LO244K-D), Pedospumella encystans (strain

JBMS11), Poterioochromonas malhamensis (strain DS), Poteriospumella lacustris (strain

JBC07), Poteriospumella lacustris (strain JBM10), Poteriospumella lacustris (strain JBNZ41),

93

94

Pedospumella sinomuralis (strain JBCS23), Spumella bureschii (strain JBL14), Spumella

lacusvadosi (strain JBNZ39), Spumella vulgaris (strain 199hm), Synura sp. (strain LO234KE), and Uroglena sp. (strain WA34KE). The data are available at the European Nucleotide Archive accession PRJEB13662.

Here these data were compared to a query database of nine meiosis-specific and 30 meiosisrelated genes established by Chi et al. (2014a). This database was originally established using literature and keyword searches of the NCBI protein database and the Uniprot Knowledgebase. Using local scripts, two methods were used for comparing the transcriptomic data to the query database of meiotic genes: BlastP (Altschul et al. 1990) and HMMER v3.0 (Eddy 2011).

Reciprocal BLAST analysis were also performed using BLASTP against the non-redundant protein sequence database of NCBI. The parameters for BLASTp and HMMER is default, except sequences were retained if they had hits with E-values $<10 \mathrm{E}-4$. Following Saccharomyces cerevisiae nomenclature, gene names are signified in italic capital letters, and proteins in lowercase except first letter. 


\section{Results}

108 Out of the 39 meiotic genes, 38 were identified in the transcriptomes of 18 chrysophytes strains

109 (Table 1, Supplementary File 1). For the nine meiosis-specific genes, all of them were found in 110 at least six transcriptomes. In particular, SPO11, which initiates meiosis through double-strand 111 DNA breaks in most eukaryotes (Keeney et al. 1997) except in some amoebae (Bloomfield

112 2018), was found in seven strains. The following other meiosis-specific genes were found:

113 DMC1 in 15 strains, is important for recombination homolog bias (Bugreev et al. 2011); HOP2

114 in 18 strains, stabilizes the association of the protein Dmc1 with DNA (Chen et al. 2004); MND1

115 in 12 strains, also stabilizes the association of the protein Dmc1 with DNA (Chen et al. 2004);

116 HOP1 in six strains, forms part of the synaptonemal complex (Hollingsworth et al. 1990); REC8

117 in 12 strains, forms part of the sister chromatid cohesin complex (Howard-Till et al. 2013);

118 MER3 in 16 strains, is a DNA helicase (Nakagawa \& Kolodner 2002); and MSH4 in 14 strains

119 and MSH5 in 13 strains, which are heterodimers that stabilize recombination intermediates

120 (Nishant et al. 2010; Snowden et al. 2004).

For the 30 meiosis-related genes, 29 were found in at least five out of the 18

122 transcriptomes. The only gene that was not found in any transcriptome was REC114. The

123 meiosis-related gene MMS4 was found in the smallest amount of five transcriptomes. The seven

124 meiosis-related genes MPH1, PMS1, RAD23, RAD50, SGS1, SMC5 and SMC6 were found in all

12518 transcriptomes. Nine of the other meiosis-related genes were only not present in two or three

126 chrysophyte transcriptomes.

127 Many of the missing meiotic genes could really be missing from the genomes, or the 128 genes could be missing because of how the data was generated. In transcriptomes, just like in 129 ESTs (Chi et al. 2014b), missing genes are expected because only genes being actively expressed 
130 will be sequenced. These differences between the sequences of strains of the same species here 131 suggest that indeed the transcriptomes are likely missing a lot of non-expressed genes. For 132 example, HOP1 is only found in two of three strains of Poteriospumella lacustris, and MSH4 133 and MSH5 is only found in one of two stains of Dinobryon sp. 


\section{Discussion}

135 In this gene inventory of chrysophyte transcriptomes, we found evidence for the presence of 136 many meiosis-specific and meiosis-related genes. If we assume a use-it-or-lose-it view of these

137 genes (Normark et al. 2003; Schurko \& Logsdon 2008), then the chrysophytes are using the 138 protein products of these genes to construct functional meiotic machinery. As with most other eukaryotes (Dunthorn \& Katz 2010; O’Malley et al. 2013), the chrysophytes are therefore likely sexual, which supports earlier microscopic observations that potentially indicated sex (Bourrelly 1957; Fott 1959; Sandgren 1983; Wawrik 1972). If this is the case, and even if sex has not yet been directly observed, the genetic diversity and adaptive evolution of the chrysophytes would benefit from this secretive sex. And this benefit could occur even if sex was a rare event in the chrysophytes (D'Souza \& Michiels 2010; Green \& Noakes 1995).

Additionally, we found meiotic genes involved in both crossover pathways, including genes involved in making the synaptonemal complex in class I pathway. Although these pathways have been differentially lost in various eukaryotic groups (Chi et al. 2014a; Loidl 2016), chrysophyte potentially use both of these pathways. Given the phylogenetic placement across the chrysophyte tree of life of the 15 species sampled here (Beisser et al. 2017), these results supporting secretive sex and the presence of both crossover pathways should be applicable for all, or most, other chrysophyte species. thorough de novo genome sequencing of different chrysophyte species should be performed to 
157 as these observations will offer the best evidence that the chrysophyte are truly sexual in nature

158 and that meiosis in these protists is not being used just for automixis. 


\section{Funding}

160 The Deutsche Forschungsgemeinschaft provided support to MD (grant \# DU1319/1- 1) and JB

161 (grant \#s BO3245/17 and BO3245/19).

162

\section{Grant Disclosures}

164 The following grant information was disclosed by the authors:

165 Deutsche Forschungsgemeinschaft: \#DU1319/1-1.

166 Deutsche Forschungsgemeinschaft: \#BO3245/17.

167 Deutsche Forschungsgemeinschaft: \# BO3245/19.

168

\section{Competing Interests}

170 The authors declare there are no competing interests.

171

\section{Author Contributions}

173 - Diana Kraus, Jingyun Chi, and Micah Dunthorn conceived and designed the experiments, 174 performed the experiments, analyzed the data, wrote the paper, prepared figures and tables.

175 - Jens Boenigk, Daniela Beisser, and Nadine Graupner contributed data, analyzed the data, wrote 176 the paper, and reviewed drafts of the paper. 
177

178

179

180

181

182

183

184

185

186

187

188

189

190

191

192

193

194

195

196

197

198

199

200

201

202

203

204

205

206

207

208

209

210

\section{References}

Altschul SF, Fish W, Miller W, Myers EW, and Lipman DJ. 1990. Basic local alignment search tool. J Mol Biol 215:403-410.

Andrews S. 2012. FastQC a quality control tool for high throughput sequence data. Available at http:// www.bioinformatics.babraham.ac.uk/projects/fastqc/.

Beisser D, Graupner N, Bock C, Wodniok S, Grossmann L, Vos M, Sures B, Rahmann S, and Boenigk J. 2017. Comprehensive transcriptome analysis provides new insights into nutritional strategies and phylogenetic relationships of chrysophytes. PeerJ 5:e2832. 10.7717/peerj.2832

Bell G. 1982. The masterpiece of nature: the evolution and genetics of sexuality. Berkeley: University of California Press.

Bloomfield G. 2018. Spol1-independent meiosis in social amoebae. Annu Rev Microbiol 72:293-307. 10.1146/annurev-micro-090817-062232

Boenigk J. 2008. Nanoflagellates: functional groups and intraspecific variation. Denisia 23:331335.

Boenigk J, and Arndt H. 2002. Bacterivory by heterotrophic flagellates: community structure and feeding strategies. Antonie Van Leeuwenhoek 81:465-480.

Bourrelly P. 1957. Recherches sur les Chrysophycées. Revue Algologique Mémoire Hors Série $1: 1-412$.

Bugreev DV, Pezza RJ, Mazina OM, Voloshin ON, Camerini-Otero RD, and Mazin AV. 2011. The resistance of DMC1 D-loops to dissociation may account for the DMC1 requirement in meiosis. Nature Struct Mol Biol 18:56-61.

Chen YK, Leng CH, Olivares H, Lee MH, Chang YC, Kung WM, Ti SC, Lo YH, Wang AHJ, Chang CS, Bishop DK, Hsueh YP, and Wang TF. 2004. Heterodimeric complexes of Hop2 and Mnd1 function with Dmc1 to promote meiotic homolog juxtaposition and strand assimilation. Proc Natl Acad Sci USA 101:10572-10577.

Chi J, Mahé F, Loidl J, Logsdon J, and Dunthorn M. 2014a. Meiosis gene inventory of four ciliates reveals the prevalence of a synaptonemal complex-independent crossover pathway. Mol Biol Evol 31:660-672.

Chi J, Parrow MW, and Dunthorn M. 2014b. Cryptic sex in Symbiodinium (Alveolata, Dinoflagellata) is supported by an inventory of meiotic genes. J Eukaryot Microbiol 61:322-327.

Corradi N, and Brachmann A. 2017. Fungal mating in the most widespread plant symbionts? Trends Plant Sci 22:175-183. http://dx.doi.org/10.1016/j.tplants.2016.10.010 
211

212

213

214

215

216

217

218

219

220

221

222

223

224

225

226

227

228

229

230

231

232

233

234

235

236

237

238

239

240

241

242

243

D'Souza TG, and Michiels NK. 2010. The costs and benefits of occasional sex: theoretical predictions and a case study. J Heredity 101:S34-S41. 10.1093/jhered/esq005

del Campo J, and Massana R. 2011. Emerging diversity within chrysophytes, choanoflagellates and bicosoecids based on molecular surveys. Protist 162:435-448.

Dunthorn M, and Katz LA. 2010. Secretive ciliates and putative asexuality in microbial eukaryotes. Trends Microbiol 18:183-188.

Dunthorn M, Zufall RA, Chi J, Paszkiewicz K, Moore K, and Mahé F. 2017. Meiotic genes in colpodean ciliates support secretive sexuality. Genome Biol Evol 9:1781-1787.

Eddy SR. 2011. Accelerated profile HMM searches. PLOS Comput Biol 7.

Ekelund F, Ronn R, and Griffiths BS. 2001. Quantitative estimation of flagellate community structure and diversity in soil samples. Protist 152:301-314.

Finlay BJ, and Esteban GF. 1998. Freshwater protozoa: biodiversity and ecological function. Biodiversity and Conservation 7:1163-1186.

Foissner W. 1987. Soil protozoa: fundamental problems, ecological significance, adaptations in ciliates and testaceans, bioindicators, and guide to the literature. Prog Protistol 2:69-212.

Fott B. 1959. Zur Frage der Sexualität bei den Chrysomonaden. Nova Hedwigia 1:115-129.

Grabherr MG, Haas BJ, Yassour M, Levin JZ, Thompson DA, Amit I, Adiconis X, Fan L, Raychowdhury R, Zeng Q, Chen Z, Mauceli E, Hacohen N, Gnirke A, Rhind N, di Palma F, Birren BW, Nusbaum C, Lindblad-Toh K, Friedman N, and Regev A. 2011. Full-length transcriptome assembly from RNA-Seq data without a reference genome. Nature Biotechnol 29:644-652.

Graupner N, Jensen M, Bock C, Marks S, Rahmann S, Beisser D, and Boenigk J. 2018. Evolution of heterotrophy in chrysophytes as reflected by comparative transcriptomics. FEMS Microbiol Ecol 94: fiy039.

Green RF, and Noakes DLG. 1995. Is a little bit of sex as good as a lot? J Theor Biol 174:8796. http://dx.doi.org/10.1006/jtbi.1995.0081

Grossmann L, Bock C, Schweikert M, and Boenigk J. 2016. Small but manifold: hidden diversity in 'Spumella-like flagellates'. J Eukaryot Microbiol 63:419-439.

Hollingsworth NM, Goetsch L, and Byers B. 1990. The HOP1 gene encodes a meiosisspecific component of yeast chromosomes. Cell 61:73-84.

Howard-Till RA, Lukaszewicz A, Novatchkova M, and Loidl J. 2013. A single cohesin complex performs mitotic and meiotic functions in the protist Tetrahymena. PLoS Genet 9:e1003418. 10.1371/journal.pgen.1003418 
244

Jost S, Medinger R, and Boenigk J. 2010. Cultivation independent species identification of Dinobryon sp. (Chrysophyceae) by means of multiplex single cell PCR (MSC-PCR). $J$ Phycol 46:901-906.

Keeney S, Giroux CN, and Kleckner. 1997. Meiosis-specific DNA double-strand breaks are catalyzed by Spo11, a member of a widely conserved protein domain. Cell 88:375-384.

Kristiansen J, and Preisig HR. 2001. Encyclopedia of chrysophyte genera. Berlin: J. Cramer.

Kristiansen J, and Škaloud P. 2017. Chrysophyta. In: Archibald JM, Simpson AGB, Slamovits $\mathrm{CH}$, Margulis L, Melkonian M, Chapman DJ, and Corliss JO, eds. Handbook of the Protists. Cham: Springer.

Loidl J. 2016. Conservation and variability of meiosis across the eukaryotes. Annu Rev Genet 50:293-316. 10.1146/annurev-genet-120215-035100

Malik S-B, Pightling AW, Stefaniak LM, Schurko AM, and Logsdon JM. 2008. An expanded inventory of conserved meiotic genes provides evidence for sex in Trichomonas vaginalis. PLoS ONE 3:e2879.

Martin M. 2011. Cutadapt removes adapter sequences from high-throughput sequencing reads. EMBnetjournal 17:1012. 10.14806/ej.17.1.200

Maynard Smith J. 1978. The evolution of sex. Cambridge: Cambridge University Press.

Nakagawa T, and Kolodner RD. 2002. Saccharomyces cerevisiae Mer3 Is a DNA helicase involved in meiotic crossing over. Mol Cellular Biol 22:3281-3291.

Nishant KT, Chen C, Shinohara M, Shinohara A, and Alani E. 2010. Genetic analysis of baker's yeast Msh4-Msh5 reveals a threshold crossover level for meiotic viability. PLoS Genetics 6:e1001083.

Normark BB, Judson OP, and Moran NA. 2003. Genomic signatures of ancient asexual lineages. Biol J Linn Soc 79:69-84.

O'Gorman CM, Fuller HT, and Dyer PS. 2009. Discovery of a sexual cycle in the opportunistic fungal pathogen Aspergillus fumigatus. Nature 457:471-474.

O'Malley MA, Simpson AGB, and Roger AJ. 2013. The other eukaryotes in light of evolutionary protistology. Biol Philos 28:299-330.

Patil S, Moeys S, von Dassow P, Huysman MJJ, Mapleson D, De Veylder L, Sanges R, Vyverman W, Montresor M, and Ferrante MI. 2015. Identification of the meiotic toolkit in diatoms and exploration of meiosis-specific SPO11 and RAD51 homologs in the sexual species Pseudo-nitzschia multistriata and Seminavis robusta. BMC Genomics 16:930. 10.1186/s12864-015-1983-5 
Ramesh MA, Malik S-B, and Longsdon JM. 2005. A phylogenomic inventory of meiotic genes: evidence for sex in Giardia and an early eukaryotic origin of meiosis. Curr Biol 15:185-191.

Sandgren CD. 1983. Survival strategies of chrysophyte flagellates: reproduction and formation of resistant spores. In: Fryxell G, ed. Survival strategies in the algae Cambridge: Cambridge University Press, 23-48.

Sandgren CD. 1988. The ecology of chrysophyte flagellates: their growth and perennation strategies as freshwater phytoplankton. In: Sandgren CD, ed. Growth and reproductive strategies of freshwater phytoplankton. Cambridge: Cambridge University Press, 9-104.

Schurko AM, and Logsdon JM. 2008. Using a meiosis detection toolkit to investigate ancient asexual "scandals" and the evolution of sex. BioEssays 30:579-589.

Schurko AM, Neiman M, and Logsdon JM. 2009. Signs of sex: what we know and how we know it. Trends Ecol Evol 24:208-217.

Scoble JM, and Cavalier-Smith T. Scale evolution in Paraphysomonadida (Chrysophyceae): sequence phylogeny and revised taxonomy of Paraphysomonas, new genus Clathromonas, and 25 new species2014. Eur J Protistol 50:551-592.

Siver PA, and Lott AM. 2016. Descriptions of two new species of Synurophyceae from a bog in Newfoundland, Canada: Mallomonas baskettii sp. nov. and Synura kristiansenii sp. nov. Nova Hedwigia 102:501-511.

Snowden T, Acharya S, Butz C, Berardini M, and Fishel R. 2004. hMSH4-hMSH5 recognizes Holliday junctions and forms a meiosis-specific sliding clamp that embraces homologous chromosomes. Mol Cell 15:437-451.

Speijer D, Lukeš J, and Eliáš M. 2015. Sex is a ubiquitous, ancient, and inherent attribute of eukaryotic life. Proc Natl Acad Sci USA 112:8827-8834.

Tekle YI, Wood FC, Katz LA, Cerón-Romero MA, and Gorfu LA. 2017. Amoebozoans are secretly but ancestrally sexual: evidence for sex genes and potential novel crossover pathways in diverse groups of amoebae. Genome Biol Evol 9:375-387. $10.1093 / \mathrm{gbe} / \mathrm{evx} 002$

Wawrik F. 1972. Isogame Hologamie in der Gattung Mallomonas Perty. Nova Hedwigia 23:353-362.

Wolfe AP, and Siver PA. 2013. A hypothesis linking chrysophyte microfossils to lake carbon dynamics on ecological and evolutionary time scales. Global Planet Change 111:189198. 


\section{Table $\mathbf{1}$ (on next page)}

Meiosis genes inventoried in the transcriptomes of 18 strains of 15 species of chrysophytes. 


\begin{tabular}{|c|c|c|c|c|c|c|c|c|c|c|c|c|c|c|c|c|c|c|}
\hline \multirow[b]{2}{*}{ Gene } & \multicolumn{18}{|c|}{ Chrysophyte species } \\
\hline & 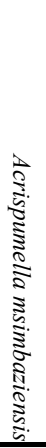 & 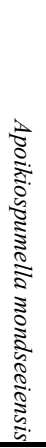 & 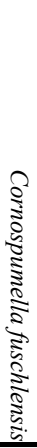 & 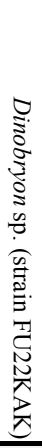 & 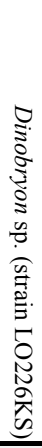 & 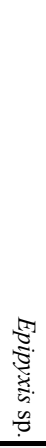 & 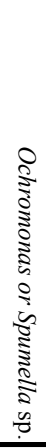 & 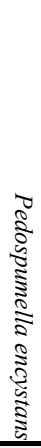 & 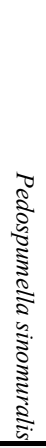 & 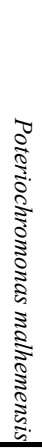 & 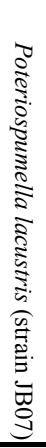 & 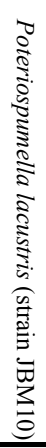 & 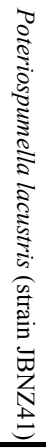 & 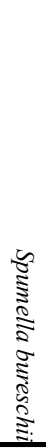 & 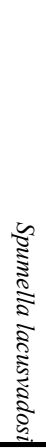 & 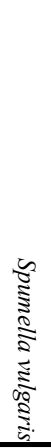 & 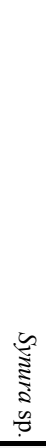 & 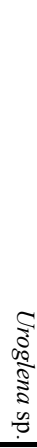 \\
\hline \multicolumn{19}{|c|}{ Double-strand break formation } \\
\hline REC114 & - & - & - & - & - & - & - & - & - & - & - & - & - & - & - & - & - & - \\
\hline SPO11 & - & - & + & - & - & + & - & + & + & - & - & - & - & + & - & + & + & - \\
\hline \multicolumn{19}{|c|}{ Crossover regulation } \\
\hline $\mathrm{DMC} 1$ & + & + & + & + & - & + & + & + & + & + & + & + & + & + & + & + & - & - \\
\hline HOP1 & - & - & - & - & - & + & - & - & + & - & - & + & + & - & - & + & - & + \\
\hline HOP2 & + & + & + & + & + & + & + & + & + & + & + & + & + & + & + & + & + & + \\
\hline MER3 & - & + & + & + & - & + & + & + & + & + & + & + & + & + & + & + & + & + \\
\hline MND1 & - & - & + & + & - & + & - & + & - & + & + & + & + & + & + & - & + & + \\
\hline MSH4 & - & + & + & + & - & + & - & + & + & + & + & + & + & + & + & + & + & - \\
\hline MSH5 & - & - & + & + & - & + & - & + & + & + & + & + & + & + & + & + & + & - \\
\hline \multicolumn{19}{|c|}{ Double-strand break repair } \\
\hline REC8 & - & - & + & + & - & + & - & + & + & + & + & + & + & + & + & + & - & - \\
\hline \multicolumn{19}{|c|}{ Bouquet formation } \\
\hline SAD1 & - & - & + & + & - & + & - & + & + & + & + & + & + & + & + & + & - & + \\
\hline \multicolumn{19}{|c|}{ DNA damage sensing/response } \\
\hline MRE11 & - & - & + & + & - & + & - & + & + & + & + & + & - & + & - & + & - & - \\
\hline RAD17 & + & + & + & + & - & + & + & + & + & + & + & + & + & + & + & - & + & - \\
\hline RAD23 & + & + & + & + & + & + & + & + & + & + & + & + & + & + & + & + & + & + \\
\hline RAD24 & + & - & + & + & + & + & + & + & + & + & + & + & + & + & + & + & + & + \\
\hline RAD50 & + & + & + & + & + & + & + & + & + & + & + & + & + & + & + & + & + & + \\
\hline NBS1 & - & - & + & + & - & - & - & - & + & + & + & + & + & + & + & - & - & + \\
\hline \multicolumn{19}{|c|}{ Double-strand break repair (nonhomology end join) } \\
\hline KU & - & - & + & + & - & + & - & + & + & + & + & + & + & + & - & + & + & - \\
\hline LIG4 & + & - & + & + & - & + & - & + & + & + & + & + & + & + & + & + & - & + \\
\hline LIF1 & - & - & - & - & - & - & - & - & - & - & - & - & - & - & - & - & - & - \\
\hline \multicolumn{19}{|c|}{ Recombinational repair } \\
\hline DNA2 & - & + & + & + & - & + & - & + & + & + & + & + & + & + & + & + & + & + \\
\hline MMS4 & - & - & - & - & - & + & - & + & - & - & - & - & - & + & - & + & + & - \\
\hline EME1 & - & - & - & - & - & - & - & - & - & - & - & - & - & - & - & - & - & - \\
\hline EXO1 & - & - & + & + & - & + & - & + & + & + & + & + & + & + & - & + & + & + \\
\hline FEN1 & + & - & + & + & + & + & + & + & + & + & + & + & + & + & + & + & + & + \\
\hline MLH1 & + & - & + & + & - & - & + & + & + & + & + & - & + & + & + & + & + & - \\
\hline MLH3 & - & + & + & + & + & + & + & + & + & + & + & + & + & + & + & + & + & - \\
\hline MPH1 & + & + & + & + & + & + & + & + & + & + & + & + & + & + & + & + & + & + \\
\hline MSH2 & - & - & + & + & - & + & - & + & + & + & + & + & + & + & + & + & + & - \\
\hline MSH6 & + & - & + & + & - & + & - & + & + & + & + & + & + & + & + & + & + & + \\
\hline MUS81 & - & - & + & + & - & + & + & + & + & + & + & + & + & + & + & + & - & - \\
\hline PMS1 & + & + & + & + & + & + & + & + & + & + & + & + & + & + & + & + & + & + \\
\hline RAD51 & + & + & + & + & - & + & + & + & + & + & + & + & + & + & + & + & - & - \\
\hline RAD52 & - & - & - & - & + & - & - & - & - & - & + & + & - & + & - & - & - & - \\
\hline RAD54 & - & + & + & + & + & + & + & + & + & + & + & + & + & + & + & + & + & + \\
\hline RTEL & - & - & + & + & - & + & - & + & + & + & + & + & + & + & - & + & - & - \\
\hline SAE2 & + & - & + & + & - & + & + & + & + & + & + & + & + & + & + & + & + & + \\
\hline SLX1 & - & - & + & + & - & + & - & + & + & - & + & + & + & + & - & - & + & - \\
\hline SLX4 & + & - & + & - & + & + & + & + & + & - & - & - & - & + & + & + & - & - \\
\hline SMC5 & + & + & + & + & + & + & + & + & + & + & + & + & + & + & + & + & + & + \\
\hline SMC6 & + & + & + & + & + & + & + & + & + & + & + & + & + & + & + & + & + & + \\
\hline GEN1 & - & - & + & + & - & + & - & + & + & + & + & + & + & + & - & + & + & - \\
\hline
\end{tabular}

